DOI: https://doi.org/10.47405/mjssh.v5i11.549

\begin{tabular}{|c|c|}
\hline 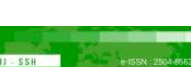 & Malaysian Journal of Social Sciences and Humanities (MJSSH) \\
\hline Malaysian Journal of & Volume 5, Issue 11, November 2020 \\
\hline (MJ-ssH) & e-ISSN : 2504-8562 \\
\hline & $\begin{array}{l}\text { Journal home page: } \\
\text { www.msocialsciences.com }\end{array}$ \\
\hline
\end{tabular}

\title{
Analisis Domain Kognitif bagi Latihan dalam Buku Teks Matematik Tahun 6
}

\author{
Cheng Jia Wei ${ }^{1}$, Roslinda Binti Rosli ${ }^{1}$ \\ ${ }^{1}$ Fakulti Pendidikan, Universiti Kebangsaan Malaysia (UKM) \\ Correspondence: Cheng Jia Wei (p99519@siswa.ukm.edu.my)
}

\begin{abstract}
Abstrak
Buku teks merupakan salah satu alat bantu mengajar yang penting dalam pendidikan matematik. Justeru, kajian ini bertujuan untuk meninjau dan meneroka domain kognitif bagi latihan-latihan dalam buku teks matematik tahun 6 Sekolah Kebangsaan (SK) dan Sekolah Jenis Kebangsaan Cina (SJKC). Kajian ini menggunakan analisis kandungan di mana latihan dalam buku teks matematik dikelaskan dari segi jenis latihan dan domain kognitif. Hasil kajian menunjukkan bahawa sebahagian besar latihan matematik dalam kedua-dua buku teks matematik berada dalam domain mengetahui. Peratusan latihan matematik berdasarkan jenis latihan, domain kognitif dan tajuk telah menunjukkan tidak terdapat perbezaan yang ketara dalam kedua-dua buku teks matematik SK dan SJKC. Walaupun menggunakan kurikulum matematik yang sama dalam semua sekolah rendah, usaha penambahbaikan buku teks harus diteruskan untuk mengurangkan jurang tahap isi kandungan buku teks agar dapat memenuhi keperluan pelajar dan keperluan semasa.
\end{abstract}

Kata kunci: buku teks, domain kognitif, latihan, analisis kandungan, matematik

\section{A Comparative Analysis on Cognitive Domain for Exercises in Year 6 Mathematics Textbooks}

\begin{abstract}
Textbook is one of the important teaching aids in mathematics education. Thus, this study aims to explore and investigate the cognitive domain for exercises in SK and SJKC mathematics textbooks. This study adopted content analysis where exercises in mathematics textbooks are classified in terms of types of exercises and cognitive domains. The results of the study showed that a large percentage the mathematics exercises in both mathematics textbooks are in the 'knowing' domain and there is no significant difference in both SK and SJKC mathematics textbooks. Despite using the same mathematics curriculum in all types of primary schools, efforts to improve the quality of the textbooks should continue to reduce the gap in textbook content levels in order to make sure that students of different abilities can benefit.
\end{abstract}

Keywords: textbook, cognitive domain, exercise, content analysis, mathematics 


\section{Pengenalan}

Di Malaysia, tujuan sekolah ditubuhkan adalah untuk mengembangkan potensi individu melalui pendidikan berkualiti dengan menyediakan generasi baru yang mampu berfikir dan menjadi warganegara yang komited (KPM, 2011). Oleh itu, Kementerian Pendidikan Malaysia (KPM) sentiasa memeriksa kurikulum secara berterusan untuk melengkapkan pelajar dengan pengetahuan, kemahiran dan nilai agar mereka dapat menghadapi cabaran masa depan dan memenuhi keperluan negara. Sehubungan dengan itu, buku teks matematik yang selaras dengan kurikulum yang dibina juga sentiasa dikemas kini untuk penambahbaikan demi menjadikan isi kandungan pembelajaran lebih sempurna.

Menurut Wong (2019), sistem pendidikan di Malaysia adalah kompleks kerana Malaysia dibentuk oleh masyarakat yang berbilang etnik. Pada tahun 1956, Laporan Penyata Razak telah menggariskan dasar pendidikan negara selepas merdeka dan mengiktiraf kewujudan pelbagai aliran pendidikan dan membenarkan penerapan bahasa ibunda sebagai medium pengajaran di sekolah. Tambahan pula, laporan tersebut turut menggolongkan sekolah rendah kepada dua jenis, iaitu sekolah rendah standard dan sekolah rendah jenis standard. Kedua-dua jenis tersebut telah menjadi prototaip kepada kewujudan Sekolah Kebangsaan (SK) dan Sekolah Rendah Jenis Kebangsaan (SJK). SJK kemudian telah terbahagi kepada dua jenis, iaitu Sekolah Rendah Jenis Kebangsaan Cina (SJKC) dan Sekolah Rendah Jenis Kebangsaan Tamil (SJKT).

SK dan SJK ialah sekolah yang dibiayai sepenuhnya oleh KPM dan dikira sebagai sekolah bantuan kerajaan (KPM, 2017). Kurikulum dan sukatan pelajaran SK dan SJK adalah sama, yang berbeza cuma bahasa penghantar yang digunakan. Dengan menggunakan sukatan kurikulum yang sama, KPM dapat memastikan perkembangan kognitif dan ilmu pengetahuan pelajar tanpa mengira aliran sekolah, bangsa dan kaum. Sehubungan dengan itu, buku teks matematik SK dan SJK merangkumi sukatan pelajaran yang sama walaupun diterbitkan dalam bahasa yang berlainan. Justeru, adalah penting bagi seseorang pendidik dalam memahami dan mengenal pasti perbezaan domain kognitif bagi latihan-latihan yang terdapat dalam buku teks matematik SK dan SJKC.

\section{Sorotan Literatur}

\section{Peranan Buku Teks Dalam Pendidikan Matematik}

Menurut Gracin (2018), buku teks memainkan peranan yang penting dalam pengajaran dan pembelajaran matematik. Peranan buku teks dalam pengajaran dan pembelajaran telah banyak dikaji oleh penyelidik seluruh dunia. Meta analisis yang dilakukan oleh Shepin (2019) mendedahkan bahawa penyelidik secara amnya bersetuju bahawa buku teks bertindak sebagai media penyampai utama dalam kurikulum dan mempunyai pengaruh yang besar dalam pendidikan masa kini. Buku teks yang dicipta adalah untuk menterjemah dasar kurikulum yang abstrak agar dapat dilaksanakan oleh guru dan pelajar dan ia berperanan sebagai perantara antara pembangunan dasar kurikulum dan guru. Buku teks matematik dapat membekalkan guru kandungan matematik yang akan diajar, pedagogi, strategi pengajaran dan aktiviti yang boleh dilakukan semasa proses pengajaran dan pembelajaran (Nie et al., 2013). Buku teks juga sangat penting dalam membantu pelajar memahami topik yang akan dipelajari dalam kurikulum, aktiviti dan latihan yang boleh dilakukan dalam kelas.

Menurut Brehmer et al. (2016), sumber utama untuk pelajar dalam bilik darjah adalah buku teks kerana ia berfungsi sebagai media untuk mengembangkan pemahaman mereka mengenai konsep matematik. Popp (2018) pula menyatakan bahawa buku teks membekalkan satu struktur dalam mempersembahkan sukatan pelajaran. Pada kebanyakan masa, guru dibekalkan kurikulum matematik manakala pelajar tidak mempunyai akses kepada kurikulum. Oleh itu, buku teks yang dirancang dan direka secara sistematik mengikut kurikulum telah memberikan maklumat kepada guru serta pelajar mengenai kurikulum tanpa merujuk kepada kurikulum itu sendiri. Tambahan lagi, rupa buku teks telah direka sedemikian untuk menjadikannya lebih menarik secara visual serta dapat merangsang minat pelajar terhadap subjek tersebut. Secara tidak langsung, buku teks telah menjadikan pembelajaran lebih mudah 
dan sangat membantu dalam mencapai hasil pembelajaran seperti yang ditetapkan dalam kurikulum (Ebrahim \& Mohamed Najib, 2014).

Selain itu, buku teks memastikan kualiti kandungan yang diberikan kepada pelajar. Pembangunan dan pembinaan buku teks adalah berdasarkan kepada teori pembelajaran dan reka bentuk adalah mengikut keperluan konteks pendidikan semasa. Oleh itu, buku teks adalah satu alat yang berkesan untuk guru sehingga mereka dapat menggunakan lebih banyak masa dalam pengajaran dan bukannya dalam menghasilkan bahan pembelajaran untuk pelajar. Buku teks matematik membantu pelajar belajar matematik dalam dua cara, iaitu pelajar dapat membaca contoh dan penjelasan yang terdapat dalam buku teks serta melakukan latihan dan menyelesaikan masalah dari buku teks (Kletzien \& Dreher, 2017). Oleh sebab buku teks adalah sumber utama di Malaysia, maka buku teks matematik mesti mengandungi latihan-latihan matematik yang membantu pelajar mengembangkan kemahiran berfikir secara kritis.

Tambahan pula, buku teks membantu menyeragamkan pengajaran di seluruh negara. Penggunaan buku teks yang sama akan memastikan bahawa pelajar dari bilik darjah yang berbeza akan diajar kandungan yang serupa dengan mereka yang dinilai oleh peperiksaan berpusat. Buku teks matematik tidak hanya direka untuk menjadi instrumen pembelajaran, tetapi ia juga dapat dianggap sebagai alat untuk mengembangkan kemahiran matematik melalui masalah matematik berstruktur yang baik disediakan dalam buku teks (Boerman-Cornell et al., 2016). Walaupun penyelidik yang berbeza menyatakan pelbagai peranan buku teks yang berbeza dalam pengajaran dan pembelajaran matematik, tetapi semua literatur ini menunjukkan bahawa buku teks memainkan peranan yang sangat penting dalam pengajaran dan pembelajaran matematik.

\section{Metod Kajian}

Buku teks ialah sumber utama bagi guru untuk memahami kurikulum yang digubal (Kai et al., 2017). Untuk menjayakan pelaksanaan pembelajaran abad ke-21 (PAK21), buku teks mesti mengandungi latihan-latihan yang memberi peluang kepada pelajar untuk mengembangkan kemahiran berfikir aras tinggi (KBAT). Tujuan utama penyelidikan ini adalah untuk mengenal pasti tahap domain kognitif bagi latihan yang terdapat dalam buku teks matematik tahun 6 SK dan SJKC. Justeru, tiga objektif telah ditetapkan dalam penyelidikan ini: (1) untuk mengenal pasti domain kognitif bagi latihan yang berbentuk penjelasan dan latihan yang berbentuk penilaian dalam buku teks matematik tahun 6 SK dan SJKC, (2) untuk menentukan perbezaan domain kognitif bagi latihan yang berbentuk penjelasan dan latihan yang berbentuk penilaian antara buku teks matematik tahun 6 SK dan SJKC dan (3) untuk mengenal pasti domain kognitif latihan-latihan mengikut topik dalam buku teks matematik tahun $6 \mathrm{SK}$ dan SJKC.

\section{Bahan}

Reka bentuk bagi kajian ini diadaptasi daripada kajian Brehmer Ryve dan Van Steenbrugge (2016) yang menganalisis penyelesaian masalah matematik untuk buku teks matematik menengah atas. Kajian ini dijalankan secara kualitatif dengan menggunakan kaedah analisis kandungan untuk membandingkan latihan matematik yang mengenai domain kognitif TIMSS dalam buku teks tahun 6 matematik SK (Chan \& Marzita, 2015) dan SJKC (Tan et al., 2015). Buku teks tahun 6 dipilih kerana ia merupakan tahun yang tertinggi dalam sekolah rendah tidak kira SK mahupun SJKC. Menurut Piaget (1976), kanak-kanak yang berumur 11 tahun ke atas dapat berfikir secara logik, abstrak dan tidak lagi bertumpu kepada bahan maujud. Oleh demikian, buku teks tahun 6 sesuai dipilih untuk meneroka dan meninjau kesesuaian kandungan berdasarkan perkembangan kognitif murid tahan 6. Selain itu, keduadua buku teks matematik SK dan SJKC ini merupakan buku teks rasmi yang diterbitkan di bawah kelulusan Kementerian Pendidikan Malaysia (KPM). Di Malaysia, semua buku teks dikembangkan di bawah pengawasan Bahagian Buku Teks untuk memastikan bahawa buku teks tersebut selaras dengan maksud kurikulum. 


\section{Kriteria Analitik}

Latihan matematik dalam dua buku teks matematik SK (Chan \& Marzita, 2015) dan SJKC (Tan et al., 2015) dianalisis dan dikelaskan dengan menggunakan dua jenis kriteria analitik, iaitu jenis latihan dan domain kognitif. Pertama sekali, latihan matematik dikelaskan kepada dua kategori, iaitu latihan yang berbentuk penjelasan dan latihan yang berbentuk penilaian. Semua latihan dalam buku teks yang merangkumi contoh, aktiviti berpandu, aktiviti pengayaan, soalan mencabar, latihan formatif, latihan sumatif dan latihan semakan telah dianalisis. Latihan-latihan yang dianggap sebagai latihan penjelasan adalah contoh dan aktiviti bimbangan. Dalam latihan penjelasan, pelajar dikehendaki menerangkan konsep matematik, membuat hubungan dengan idea matematik dan mengemukakan prosedur matematik. Sebaliknya, latihan penilaian merangkumi aktiviti pengayaan, soalan mencabar, latihan formatif, latihan sumatif dan latihan penyemakan di mana latihan-latihan tersebut memerlukan kemahiran pelajar dalam menilai konsep, idea dan prosedur matematik yang dikemukakan dalam buku teks. Latihan matematik yang dibina antara satu sama lain dianggap sebagai satu latihan sahaja.

Setelah jenis latihan dikelaskan, setiap latihan matematik dalam kedua-dua buku teks ini kemudian dikelaskan berdasarkan tiga domain kognitif: (1) mengetahui, (2) mengaplikasikan dan (3) menaakul berdasarkan Rangka Kerja Matematik TIMSS 2015 (Grønmo et al., 2015). Untuk latihan matematik yang dikodkan di bawah domain mengetahui, ia dianalisis lebih lanjut mengikut enam aspek: (1) mengimbas kembali, (2) mengenali, (3) mengelaskan/menyusun, (4) mengira, (5) mendapat dan (6) mengukur. Untuk latihan matematik yang dikodkan di bawah domain mengaplikasikan, ia dianalisis menurut tiga aspek: (1) menentu, (2) mewakili dan (3) melaksana. Bagi latihan matematik yang dikodkan di bawah domain menaakul, ia dianalisis mengikut enam aspek: (1) menganalisis, (2) mengintegrasi/mensintesiskan, (3) menilai, (4) membuat kesimpulan, (5) membuat generalisasi dan (6) membuat justifikasi. Rangka kerja tersebut dipilih kerana ia mempermudah domain kognitif yang diuji dalam TIMSS. Oleh disebabkan Malaysia kini lebih menumpukan pada penilaian antarabangsa dan penilaian tersebut digunakan di seluruh dunia, rangka kerja ini adalah paling sesuai digunakan untuk memberi satu pandangan yang lebih baik mengenai kajian ini kepada dunia. Penerangan bagi setiap aspek dalam ketiga-tiga domain kognitif (Grønmo et al. 2015) telah ditunjukkan dalam Jadual 1.

Jadual 1: Penerangan bagi setiap aspek dalam domain kognitif (Grønmo et al., 2015)

\begin{tabular}{|c|c|}
\hline \multicolumn{2}{|r|}{ Domain Mengetahui (Knowing Domain) } \\
\hline Aspek & Penerangan \\
\hline $\begin{array}{l}\text { Mengimbas Kembali } \\
\text { (Recall) }\end{array}$ & $\begin{array}{l}\text { Imbas kembali definisi, terminologi, sifat nombor, unit ukuran, } \\
\text { sifat geometri dan notasi (Contoh: } a \times b=a b, a+a+a=3 a \text { ) }\end{array}$ \\
\hline $\begin{array}{l}\text { Mengenali } \\
\text { (Recognize })\end{array}$ & $\begin{array}{l}\text { Kenali nombor, ungkapan, kuantiti, dan bentuk. Kenali entiti yang } \\
\text { setara dalam matematik. (Contoh: pecahan setara, perpuluhan dan } \\
\text { peratusan) }\end{array}$ \\
\hline $\begin{array}{l}\text { Mengelaskan/Menyusun } \\
\text { (Classify/Order) }\end{array}$ & $\begin{array}{l}\text { Kelaskan nombor, ungkapan, kuantiti, dan bentuk dengan sifat } \\
\text { sepunya. }\end{array}$ \\
\hline $\begin{array}{l}\text { Mengira } \\
\text { (Compute) }\end{array}$ & $\begin{array}{l}\text { Jalankan prosedur algoritma untuk }+,-, \times, \div \text { atau gabungannya } \\
\text { dengan nombor bulat, pecahan, perpuluhan dan integer. } \\
\text { Menjalankan prosedur algebra yang mudah. }\end{array}$ \\
\hline $\begin{array}{l}\text { Mendapat } \\
\text { (Retrieve) }\end{array}$ & Dapatkan maklumat dari grafik, jadual, teks atau sumber lain. \\
\hline \multirow[t]{2}{*}{$\begin{array}{l}\text { Mengukur } \\
\text { (Measure) }\end{array}$} & Gunakan alat pengukur dan memilih unit ukuran yang sesuai. \\
\hline & main Mengaplikasi (Applying Domain) \\
\hline $\begin{array}{l}\text { Menentu } \\
\text { (Determine) }\end{array}$ & $\begin{array}{l}\text { Tentukan operasi, strategi dan alat yang cekap/sesuai untuk } \\
\text { menyelesaikan masalah di mana kaedah penyelesaian tersebut } \\
\text { adalah biasa digunakan. }\end{array}$ \\
\hline $\begin{array}{l}\text { Mewakili/Model } \\
\text { (Represent/Model) }\end{array}$ & $\begin{array}{l}\text { Paparkan data dalam jadual atau grafik. Buat persamaan, } \\
\text { ketaksamaan, rajah geometri atau rajah model. Menghasilkan } \\
\text { perwakilan yang setara untuk entiti atau hubungan matematik } \\
\text { tertentu. }\end{array}$ \\
\hline
\end{tabular}


DOI: https://doi.org/10.47405/mjssh.v5i11.549

\begin{tabular}{|c|c|}
\hline $\begin{array}{l}\text { Melaksana } \\
(\text { Implement })\end{array}$ & $\begin{array}{l}\text { laksanakan strategi dan operasi untuk menyelesaikan masalah yang } \\
\text { melibatkan konsep dan prosedur matematik yang biasa } \\
\text { Domain Menaakul (Reasoning Domain) }\end{array}$ \\
\hline $\begin{array}{l}\text { Menganalisis } \\
\text { (Analyze) }\end{array}$ & $\begin{array}{l}\text { Tentukan, terangkan atau gunakan hubungan antara nombor, } \\
\text { ungkapan, kuantiti dan bentuk. }\end{array}$ \\
\hline $\begin{array}{l}\text { Mengintegrasi/Mensistesis } \\
\text { (Integrate/Synthesize) }\end{array}$ & $\begin{array}{l}\text { Hubungkan elemen pengetahuan yang berbeza, perwakilan yang } \\
\text { berkaitan dan prosedur untuk menyelesaikan masalah. }\end{array}$ \\
\hline $\begin{array}{c}\text { Menilai } \\
\text { (Evaluate) }\end{array}$ & Menilai strategi dan penyelesaian masalah alternatif. \\
\hline $\begin{array}{l}\text { Membuat Kesimpulan } \\
\text { (Draw Conclusion) }\end{array}$ & Buat kesimpulan yang sah berdasarkan maklumat dan bukti. \\
\hline $\begin{array}{l}\text { Membuat Generalisasi } \\
\text { (Generalize) }\end{array}$ & $\begin{array}{l}\text { Buat pernyataan yang mewakili hubungan dengan istilah yang } \\
\text { lebih umum dan lebih meluas. }\end{array}$ \\
\hline $\begin{array}{l}\text { Membuat Justifikasi } \\
\text { (Justify) }\end{array}$ & $\begin{array}{l}\text { Berikan hujah matematik untuk menyokong strategi atau } \\
\text { penyelesaian. }\end{array}$ \\
\hline
\end{tabular}

\section{Kaedah Analisis}

Setiap latihan matematik dalam buku teks dikodkan mengikut jenis latihan, domain kognitif dan aspeknya dalam domain kognitif. Jadual 2 memaparkan contoh untuk pemetaan latihan penjelasan dalam domain mengetahui. Jadual 3 pula menunjukkan contoh pemetaan latihan penjelasan dalam domain mengaplikasikan. Manakala Jadual 4 memaparkan contoh pemetaan latihan penilaian dalam domain menaakul.

Jadual 2: Pemetaan latihan penjelasan dalam domain mengetahui

\begin{tabular}{|c|c|c|}
\hline \multicolumn{3}{|c|}{$\begin{array}{l}\text { Latihan dalam Buku Teks SK: } \\
\text { Dapatkan jawapan dalam rajah kalkulator bagi } 235620 \text { - } 1740 \div 60 . \text { (ms 2) } \\
\text { Latihan dalam Buku Teks SJKC: } \\
\text { Bacakan hasil bagi } 88 \text { x } 97616 \text { dalam rajah kalkulator. (ms 11) }\end{array}$} \\
\hline Jenis Latihan & Latihan penjelasan & $\begin{array}{l}\text { Dikodkan sebagai latihan penjelasan kerana ia } \\
\text { adalah satu aktiviti bimbingan. }\end{array}$ \\
\hline Domain Kognitif & Mengetahui (Knowing) & $\begin{array}{l}\text { Dikodkan sebagai domain mengetahui kerana } \\
\text { ia merupakan kemahiran asas matematik. }\end{array}$ \\
\hline $\begin{array}{l}\text { Aspek dalam } \\
\text { Domain Kognitif }\end{array}$ & Mendapat (Retrieve) & $\begin{array}{l}\text { Dikodkan sebagai aspek mendapat kerana ia } \\
\text { memerlukan kemahiran mendapat maklumat } \\
\text { dari sesuatu grafik atau rajah. }\end{array}$ \\
\hline
\end{tabular}

Jadual 3: Pemetaan latihan penjelasan dalam domain mengaplikasi

\begin{tabular}{|c|c|c|}
\hline \multicolumn{3}{|c|}{ Latihan dalam Buku Teks SK: } \\
\hline \multirow{3}{*}{\multicolumn{3}{|c|}{$\begin{array}{l}\text { Pada tahun 2015, sebuah kilang mengeluarkan } \frac{1}{5} \text { juta } \mathrm{kg} \text { minyak masak untuk dieksport. Sasaran } \\
\text { pengeluaran pada setiap tahun berikutnya adalah } 2 \mathrm{kali} \text { jisim minyak masak itu berbanding } \\
\text { tahun sebelumnya. Berapakah jisim, dalam } \mathrm{kg} \text {, minyak masak yang dikeluarkan pada tahun } \\
2019 \text { ? (ms } 16 \text { ) } \\
\text { Latihan dalam Buku Teks SJKC: } \\
\text { Kedai ikan Liang Hing menjual } 0.955 \text { juta } \mathrm{kg}, \frac{3}{4} \text { juta } \mathrm{kg} \text { dan } 1037500 \mathrm{~kg} \text { ikan dari bulan } \\
\text { Januari hingga bulan Mac. Kedai ikan tersebut telah menjual berapa jumlah kg ikan dalam } \\
\text { ketiga-tiga bulan tersebut? (ms } 14)\end{array}$}} \\
\hline & & \\
\hline & & \\
\hline Jenis Latihan & Latihan penjelasan & \\
\hline Domain Kognitif & $\begin{array}{l}\text { Mengaplikasi } \\
\text { (Applying) }\end{array}$ & $\begin{array}{l}\text { Dikodkan sebagai domain mengetahui kerana } \\
\text { ia merupakan penyelesaian masalah rutin }\end{array}$ \\
\hline
\end{tabular}


DOI: https://doi.org/10.47405/mjssh.v5i11.549

\begin{tabular}{lll}
\hline Aspek dalam & Melaksana (Implement) & Dikodkan sebagai aspek melaksana kerana ia \\
Domain Kognitif & melibatkan prosedur dalam melaksanakan \\
& $\begin{array}{l}\text { strategi yang terpilih untuk menyelesaikan } \\
\text { masalah tersebut. }\end{array}$ \\
\hline
\end{tabular}

Jadual 4: Pemetaan latihan penilaian dalam domain menaakul

\begin{tabular}{|c|c|c|}
\hline \multicolumn{3}{|c|}{$\begin{array}{l}\text { Sebanyak } 2 \frac{4}{5} \text { bahagian piza diberi sama banyak kepada } 7 \text { orang kanak-kanak. Adalah setiap } \\
\left.\text { orang akan mendapat lebih daripada } \frac{1}{5} \text { bahagian pizza? Buktikan. (ms } 29\right) \\
\text { Latihan dalam Buku Teks SJKC: }\end{array}$} \\
\hline \multicolumn{3}{|c|}{$\begin{array}{l}\text { Ali merancang untuk menggunakan } 33 \% \text { daripada RM300 simpanannya untuk membeli buku } \\
\text { bacaan. Jika harga sebuah buku antara RM5 hingga RM 99, berapa buah buku yang mampu } \\
\text { dibeli oleh Ali? Berikan justifikafi anda dan buktikan. (ms 61) }\end{array}$} \\
\hline Jenis Latihan & Latihan penilaian & $\begin{array}{l}\text { Dikodkan sebagai latihan penilaian kerana ia } \\
\text { adalah satu aktiviti pengayaan. }\end{array}$ \\
\hline Domain Kognitif & $\begin{array}{l}\text { Menaakul } \\
\text { (Reasoning) }\end{array}$ & $\begin{array}{l}\text { Dikodkan sebagai domain mengetahui kerana } \\
\text { ia merupakan penyelesaian masalah rutin. }\end{array}$ \\
\hline $\begin{array}{l}\text { Aspek dalam } \\
\text { Domain Kognitif }\end{array}$ & $\begin{array}{l}\text { Membuat Justifikasi } \\
\text { (Justify) }\end{array}$ & $\begin{array}{l}\text { Dikodkan sebagai aspek membuat justifikasi } \\
\text { kerana ia memerlukan hujah dan bukti dalam } \\
\text { menyokong pendapat yang dikemukakan. }\end{array}$ \\
\hline
\end{tabular}

Latihan matematik dikodkan oleh seorang penyelidik. Untuk memberikan kesahan dan kebolehpercayaan data, dua pengulas telah mengodkan latihan matematik dan dibandingkan dengan kod penyelidik. Pengulas dilatih untuk membuat kod latihan matematik berdasarkan skema pengkodan kajian ini dan pengkodan rintis dilakukan sebelum pengekodan latihan-latihan matematik. Setiap pengulas berkod kira-kira 30\% daripada jumlah keseluruhan latihan matematik yang dianggap sebagai subsampel yang boleh dipercayai (Wimmer \& Dominick, 2012). Perjanjian antara pengekod (Intercoder agreement) mencapai lebih dari $90 \%$ untuk peratusan perjanjian (percentage agreement) dan statistik Kappa. Menurut Lombard, et al. (2002), perjanjian antara pengekod untuk peratusan perjanjian yang melebihi $90 \%$ menunjukkan ketekalan tinggi antara. Statistik Kappa dalam julat 0.81 hingga 0.99 menunjukkan hampir sempurna perjanjian (Viera \& Garrett, 2005). Justeru, terdapat persetujuan yang tinggi antara penyelidik dan pengulas.

\section{Hasil Kajian}

Latihan matematik dalam buku teks SK dan SJKC telah dianalisis. Buku teks SK mengandungi 2369 latihan matematik sedangkan buku teks SJKC mengandungi 2544 latihan matematik. Jadual 5 menunjukkan statistik deskriptif domain kognitif merentasi jenis latihan matematik dalam buku teks SK dan SJKC masing-masing.

Jadual 5: Peratusan domain kognitif

\begin{tabular}{ccccc}
\hline Domain & \multicolumn{2}{c}{ Latihan Penjelasan } & \multicolumn{2}{c}{ Latihan Penilaian } \\
\cline { 2 - 5 } Kognitif & SK & SJKC & SK & SJKC \\
\hline Mengetahui & $163(51.9)$ & $154(54.0)$ & $980(47.7)$ & $1132(50.1)$ \\
Mengaplikasi & $151(48.1)$ & $131(46.0)$ & $876(42.6)$ & $914(40.5)$ \\
Menaakul & 0 & 0 & $199(9.7)$ & $213(9.4)$ \\
Jumlah & $314(100)$ & $285(100)$ & $2055(100)$ & $2259(100)$ \\
\hline
\end{tabular}

Secara keseluruhan, sebahagian besar latihan penjelasan dan latihan penilaian berada di bawah domain mengetahui dan diikuti dengan domain mengaplikasi dan domain menaakul. Kedua-dua buku teks matematik SK dan SJKC mengandungi peratusan yang berhampiran dalam ketiga-tiga domain kognitif. 
DOI: https://doi.org/10.47405/mjssh.v5i11.549

Walau bagaimanapun, kedua-dua buku teks tersebut tidak memberikan latihan penjelasan dalam domain menaakul.

Jadual 6: Bilangan latihan bagi setiap aspek domain kognitif

\begin{tabular}{ccccc}
\hline \multirow{2}{*}{ Domain Kognitif } & \multicolumn{2}{c}{ Latihan Penjelasan } & \multicolumn{2}{c}{ Latihan Penilaian } \\
\cline { 2 - 5 } & SK & SJKC & SK & SJKC \\
\hline Mengetahui & & & & \\
Mengimbas Kembali & 0 & 0 & 0 & 0 \\
Mengenali & 31 & 29 & 82 & 113 \\
Mengelaskan/Menyusun & 13 & 9 & 21 & 43 \\
Mengira & 98 & 97 & 814 & 879 \\
Mendapat & 13 & 10 & 25 & 40 \\
Mengukur & 8 & 9 & 38 & 57 \\
Mengaplikasi & & & & \\
Menentu & 6 & 11 & 32 & 42 \\
Mewakili/Model & 26 & 27 & 47 & 58 \\
Melaksana & 119 & 93 & 797 & 814 \\
Menaakul & & & & \\
Menganalisis & 0 & 0 & 124 & 143 \\
Mengintegrasi/Mensistesis & 0 & 0 & 30 & 27 \\
Menilai & 0 & 0 & 26 & 20 \\
Membuat Kesimpulan & 0 & 0 & 7 & 8 \\
Membuat Generalisasi & 0 & 0 & 6 & 6 \\
Membuat Justifikasi & 0 & 0 & 6 & 9 \\
Jumlah & $\mathbf{3 1 4}$ & $\mathbf{2 8 5}$ & $\mathbf{2 0 5 5}$ & $\mathbf{2 2 5 9}$ \\
\hline
\end{tabular}

Jadual 6 menunjukkan bilangan latihan matematik dalam setiap aspek domain kognitif. Sebilangan besar latihan penjelasan mahupun latihan penilaian dalam domain mengetahui dikategorikan dalam aspek mengira di mana latihan-latihan tersebut melibatkan prosedur algoritma yang merupakan komponen penting dalam pembelajaran matematik. Pelajar perlu menguasai kemahiran ini kerana mereka adalah asas kepada penyelesaian masalah. Dalam domain mengaplikasi pula, kebanyakan latihan penjelasan mahupun latihan penilaian dikelaskan dalam aspek melaksana. Latihan-latihan ini melibatkan proses melaksanakan prosedur, strategi dan pemodelan yang dipilih dalam menyelesaikan sesuatu masalah matematik. Tidak terdapat latihan penjelasan dikelaskan dalam domain menaakul. Manakala kebanyakan latihan penilaian dikategorikan sebagai aspek menganalisis dalam domain menaakul kerana latihan tersebut melibatkan pola nombor yang perlu dianalisis dan dikenal pasti sebelum pelajar dapat menyelesaikan latihan tersebut. Didapati bahawa terdapat perbezaan yang tidak ketara bagi bilangan latihan buku teks matematik SK dan SJKC dalam semua aspek.

Rajah 1 merumuskan pembahagian domain kognitif merentasi semua topik dalam kedua-dua buku teks matematik SK dan SJKC. Kedua-dua buku teks matematik SK dan SJKC mempunyai topik yang sama. Sebilangan besar topik mempunyai kecenderungan yang umum iaitu peratusan domain mengetahui adalah tertinggi, diikuti dengan domain mengaplikasi dan akhirnya domain menaakul. Kedua-dua buku teks matematik SK dan SJKC tidak mempunyai jurang peratusan yang jauh dalam semua topik. 
Malaysian Journal of Social Sciences and Humanities (MJSSH), Volume 5, Issue 11, (page 116 - 126), 2020 DOI: https://doi.org/10.47405/mjssh.v5i11.549

Rajah 1: Pembahagian domain kognitif merentasi semua topik

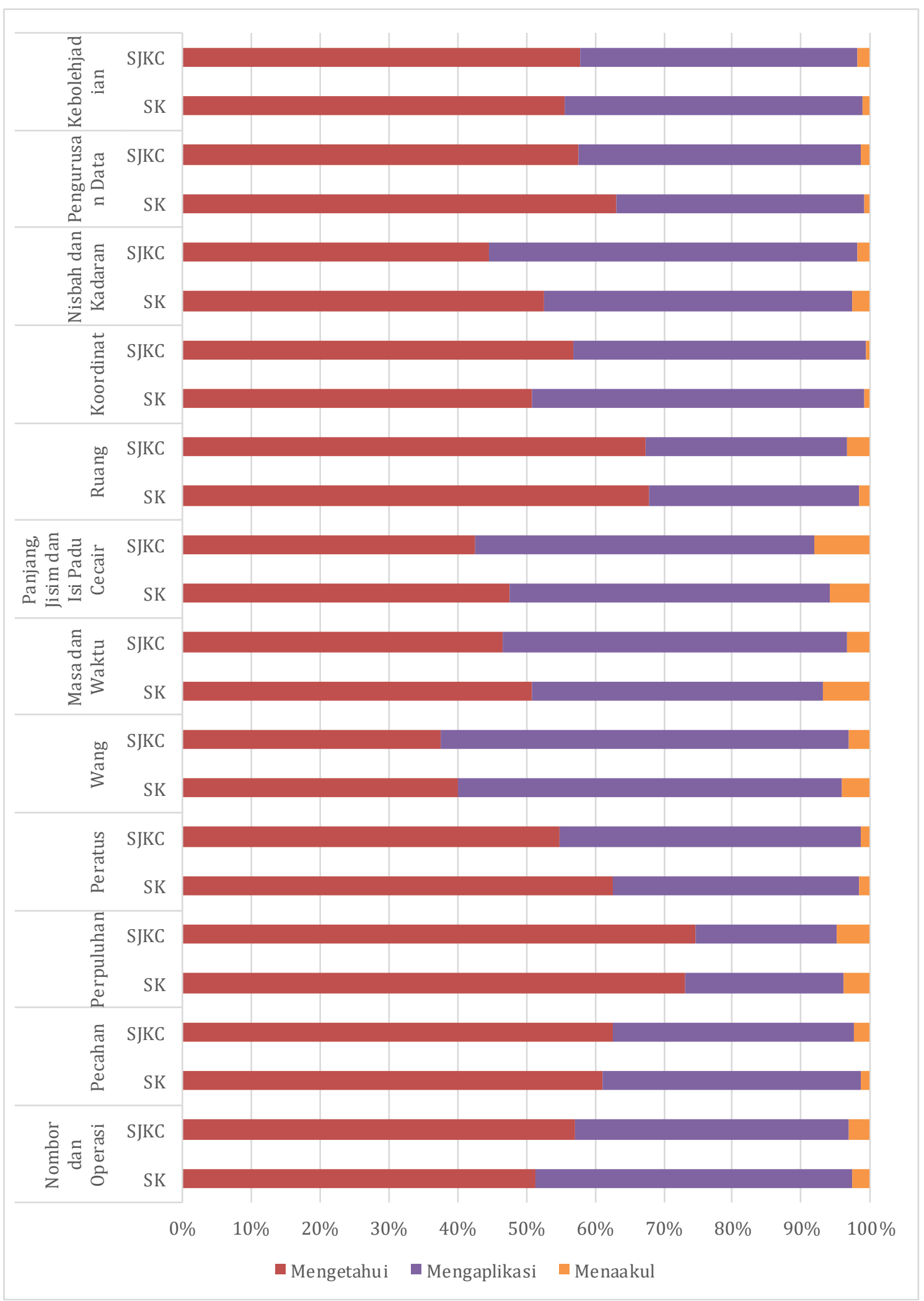




\section{Perbincangan Kajian}

Secara keseluruhan, didapati bahawa sebilangan besar latihan penjelasan mahupun latihan penilaian dalam kedua-dua buku teks matematik SK dan SJKC berada di bawah domain mengetahui. Latihanlatihan dalam domain tersebut melibatkan tahap kognitif yang rendah seperti menghafal fakta dan pengiraan asas (Villeneuve et al., 2019). Latihan-latihan ini adalah sesuai kepada murid-murid yang berusia 12 tahun kerana mereka masih digolongkan sebagai kanak-kanak. Walaupun sebahagian besar latihan dikelaskan dalam domain mengetahui, guru matematik juga perlu mempunyai fleksibiliti untuk mengubah dan melaksanakan latihan mengikut keperluan pelajarnya dalam meningkatkan pelaksanaan kurikulum. Ini adalah selaras dengan penyataan yang mengatakan guru bukan sahaja memilih dan merancang latihan matematik yang sesuai dan bermanfaat, tetapi guru juga mesti menyokong aktiviti kognitif pelajar secara konsisten (Lee et al., 2019).

Selain itu, kedua-dua buku teks matematik SK dan SJKC tidak memberikan latihan penjelasan dalam domain menaakul. Menurut Grønmo et al. (2015), domain menaakul menghendaki pelajar melakukan pemikiran logik dan pemikiran sistematik untuk menyelesaikan masalah bukan rutin. Namun, latihan penjelasan hanya memerlukan pelajar untuk menjelaskan fakta, konsep dan kadang-kadang mungkin menerapkannya dalam pengiraan mudah. Pelajar tidak perlu membuat penaakulan seperti aspek-aspek di bawah domain menaakul. Maka, tidak ada latihan penjelasan dikelaskan dalam domain menaakul.

Bilangan latihan dalam domain menaakul adalah paling kurang bagi kedua-dua jenis latihan dan buku teks. Ini adalah kerana ia memerlukan pemikiran yang kritis dalam menyelesaikan masalah yang bukan rutin. Walaupun Piaget (1972) mengatakan kanak-kanak yang berumur 11 tahun ke atas dapat berfikir secara logik, abstrak dan tidak lagi bertumpu kepada bahan maujud, namun kanak-kanak tahun 6 yang bersekolah rendah masih berada dalam permulaan perkembangan berfikiran aras tinggi. Mereka masih memerlukan bimbangan daripada guru agar memudahkan mereka menguasai sesuatu kemahiran atau pengetahuan. Sekiranya latihan-latihan banyak tertumpu pada domain menaakul, kebanyakan kanakkanak akan menghadapi cabaran dan kesukaran dalam pembelajaran matematik kerana mereka belum tersedia dari segi minda dan pemikiran.

Hasil analisis juga menunjukkan bahawa terdapat perbezaan yang tidak ketara bagi bilangan latihan buku teks SK dan SJKC. Kedua-dua buku teks mempunyai peratusan yang berhampiran dalam aspek jenis latihan, domain kognitif mahupun tajuk. Taburan domain kognitif dalam setiap topik bagi setiap latihan dalam kedua-dua buku teks juga berhampiran. Ini telah menunjukkan kualiti atau domain kognitif latihan dalam kedua-dua buku teks adalah serupa walaupun penggunaan bahasa penghantar yang berlainan.

\section{Kesimpulan}

Sebagai kesimpulannya, kajian ini telah memberikan satu gambaran mengenai domain kognitif latihanlatihan yang terdapat dalam buku teks matematik SK dan SJKC. Menurut Son (2012), pendidik perlu menyedari jurang antara kurikulum dan buku teks matematik untuk merapatkan jurang antara pelajar. Tambahan pula, kesedaran tentang kewujudan jurang kurikulum antara pelbagai aliran sekolah juga adalah sangat penting kepada guru agar sentiasa bersedia untuk meningkatkan kemahiran dan pengetahuan kendiri dalam mendidik anak murid. Para guru juga digalakkan tidak boleh bergantung hanya pada buku teks sahaja tetapi mungkin perlu menggunakan sumber yang sesuai untuk mencapai pengajaran yang berkesan.

Selain itu, kajian ini memberi implikasi kepada guru, pembangun kurikulum, pengarang buku teks, penerbit dan penyelidik. Mereka harus menyedari jurang antara buku teks matematik SK dan SJKC. Walau bagaimanapun, analisis buku teks ini tidak dapat menyimpulkan bagaimana guru menggunakan latihan-latihan matematik dalam buku teks semasa menjalankan pelajaran. Sebaliknya, ia memberikan tafsiran yang bermakna mengenai domain kognitif latihan matematik untuk dikenal pasti sama ada latihan tersebut sesuai atau perlu ditambahbaikkan dalam kurikulum. 
Analisis buku teks memberikan maklumat yang berharga mengenai bahan-bahan kurikulum. Kajian ini hanya merangkumi tahap domain kognitif dalam buku teks matematik SK dan SJKC. Kajian lanjutan boleh dilakukan dengan membandingkan ketiga-tiga buku teks matematik SK, SJKC dan SJKT dalam meninjau keseragaman tahap isi kandungan. Kajian lanjutan juga boleh dijalankan dalam membandingkan buku teks dari pelbagai negara supaya dapat memberikan pandangan mengenai persamaan dan perbezaan kurikulum antara sebuah negara dengan yang lain.

Tambahan lagi, dapatan kajian memberi satu gambaran baru kepada masyarakat mengenai aspek penting dalam penambahbaikan kurikulum di Malaysia supaya kurikulum sentiasa dapat memenuhi keperluan zaman. Dengan melaporkan domain kognitif dalam buku teks matematik SK dan SJKC, diharapkan dapat memberi kesedaran kepada penyelidik dan penulis buku teks mengenai kesesuaian latihan dan sumber matematik dalam menyelaraskan kurikulum. Kajian ini mungkin menarik bagi penerbit, penulis buku teks, guru dan pelajar kerana mereka ialah pengguna kepada buku teks. Kajian ini juga menyedarkan penulis buk teks dan guru mengenai kualiti latihan yang akan dipilih dan dilaksanakan dalam kelas. Mudah-mudahan dengan laporan ini, ia akan menerangkan kepada masyarakat sedunia mengenai kurikulum di Malaysia terutamanya dalam bidang pembinaan buku teks.

\section{Rujukan}

Boerman-Cornell, W., Klanderman, D., \& Schut, A. (2016). Using Harry Potter to Bridge Higher Dimensionality in Mathematics and High-Interest Literature. Journal of Adolescent \& Adult Literacy, 60(4), 425-432. https://doi.org/10.1002/jaal.597

Brehmer, D., Ryve, A., \& Van Steenbrugge, H. (2016). Problem solving in Swedish mathematics textbooks for upper secondary school. Scandinavian Journal of Educational Research, 60(6), 577-593. https://doi.org/10.1080/00313831.2015.1066427

Chan, Y. L., \& Marzita Puteh. (2015). Kurikulum Standard Sekolah Rendah Matematik Tahun 6 Sekolah Kebangsaan. Dewan Bahasa dan Pustaka.

Ebrahim Mohammadpour \& Mohamed Najib Abdul Ghafar. (2014). Mathematics achievement as a function of within-and between-school differences. Scandinavian Journal of Educational Research, 58(2), 189-221. https://doi.org/10.1080/00313831.2012.725097

Gracin, D. G. (2018). Requirements in mathematics textbooks: a five-dimensional analysis of textbook exercises and examples. International Journal of Mathematical Education in Science and Technology, 49(7), 1003-1024. https://doi.org/10.1080/0020739x.2018.1431849

Grønmo, L. S., Lindquist, M., Arora, A., \& Mullis, I. V. (2015). TIMSS 2015 mathematics framework. TIMSS, 11-28.

Kai, J. T., Zaleha Ismail \& Mardhiyana Abidin. (2017). A Comparative Analysis on Cognitive Domain for the Malaysian Primary Four Textbook Series. EURASIA Journal of Mathematics, Science and Technology Education 14(4): 1273-1286.

Kementerian Pendidikan Malaysia. (2011). Malaysia Education Blueprint 2013-2025. Kementerian Pendidikan Malaysia.

Kementerian Pendidikan Malaysia. (2017). Dasar Pendidikan Kebangsaan. Bahagian Perancangan dan Penyelidikan Dasar Pendidikan.

Kletzien, S. B., \& Dreher, M. J. (2017). What Experiences Do Expository Books on Recommended Book Lists Offer to K-2 Students?. Reading Psychology, 38(1), 71-96.

Lee, E., Lee, K., \& Park, M. (2019). Developing Preservice Teachers' Abilities to Modify Mathematical Tasks: Using Noticing-Oriented Activities. International Journal of Science and Mathematics Education, 17, 965-985.

Lombard, M., Snyder-Duch, J., \& Bracken, C. C. (2002). Content analysis in mass communication: Assessment and reporting of intercoder reliability. Human Communication Research, 28(4), 587604. https://doi.org/10.1111/j.1468-2958.2002.tb00826.x

Nie, B., Freedman, T., Hwang, S., Wang, N., Moyer, J. C., \& Cai, J. (2013). An investigation of teachers' intentions and reflections about using Standards-based and traditional textbooks in the classroom. ZDM, 45(5), 699-711. https://doi.org/10.1007/s11858-013-0493-7

Piaget, J. (1972). Intellectual Evolution from Adolescence to Adulthood. Human Development, 15(1), 1-12. https://doi.org/10.1159/000271225 
Popp, J. S. (2018). Teachers' Text Selections and Explanations About Text Selection and Use in History/Social Studies. Literacy Research: Theory, Method, and Practice, 67(1), 279-295. https://doi.org/10.1177/2381336918786891

Shepin, L. G. (2019). Making Authentic Literary Texts Relevant, Meaningful, and Fun in Advanced Beginner and Intermediate Spanish-language Classrooms. Hispania, 102, 313-318.

Son, J. W. (2012). A cross-national comparison of reform curricula in Korea and the US in terms of cognitive complexity: the case of fraction addition and subtraction. ZDM, 44(2), 161-174. https://doi.org/10.1007/s11858-012-0386-1

Tan, S. N., Looi, L. M., Lee, K. N., \& Lee, K. K. (2015). Kurikulum Standard Sekolah Rendah Matematik Tahun 6 Sekolah Jenis Kebangsaan Cina. Penerbitan Pelangi Sdn. Bhd.

Villeneuve, E. F., Hajovsky, D. B., Mason, B. A., \& Lewno, B. M. (2019). Cognitive ability and math computation developmental relations with math problem solving: An integrated, multigroup approach. School Psychology, 34(1), 96-108.

Weinberg, A., \& Wiesner, E. (2011). Understanding mathematics textbooks through reader-oriented theory. Educational Studies in Mathematics, 76(1), 49-63. https://doi.org/10.1007/s10649-0109264-3

Wong, K. H. (2019, August 30). Ada apa dengan sekolah cina?. Malaysiakini. 